\title{
Intelligent IoT-Based Cross-Border e-Commerce Supply Chain Performance Optimization
}

\author{
Lei Xia ${ }^{1}$ and Sitong Liu $\mathbb{D}^{2}$ \\ ${ }^{1}$ School of Economics and Management, Xi'an Aeronautical University, Xi'an, 710077 Shaanxi, China \\ ${ }^{2}$ School of Management, Guilin University of Aerospace Technology, Guilin, 541004 Guangxi, China \\ Correspondence should be addressed to Sitong Liu; liusitong@guat.edu.cn
}

Received 25 March 2021; Revised 17 May 2021; Accepted 8 June 2021; Published 22 June 2021

Academic Editor: Peng Yu

Copyright (c) 2021 Lei Xia and Sitong Liu. This is an open access article distributed under the Creative Commons Attribution License, which permits unrestricted use, distribution, and reproduction in any medium, provided the original work is properly cited.

\begin{abstract}
Internet of Things (IoT) technology can benefit automated production, agriculture, intelligent autonomous driving, and many other industries by using billions of smart devices. As a good example, intelligent IoT and 5G are the main source of information acquisition and play an important role in the multiobjective optimization process of the supply chain. This paper develops an optimal management and coordination method to improve the performance of cross-border e-commerce supply chain by using IoT tracking technique and multiobjective decision-making. The numerical results justify that our proposed scheme has high internal consistency, with the Cronbach's alpha factor of each dimension of the optimized decision model all greater than $80 \%$.
\end{abstract}

\section{Introduction}

Over the past decade, a number of emerging technologies have changed the evolving path of our life. $5 \mathrm{G}$ Internet of Things (IoT) is a global network based on standard communication protocol, which intends to collect observations from physical world and implement practical applications [1-3]. It is predicted that by $2025,75.44$ billion devices worldwide will be connected to the Internet of Things. The Internet of Things technology is the next important technology to realize the interconnection of everything in the world. In the ten years from 2020 to 2030, IoT devices will grow from 75 billion to more than 100 billion [4]. They have the characteristics of large scale, higher speed, more mode, and high data quality and heterogeneity [5]. As the main driving force of IoT, $5 \mathrm{G}$ is supposed to have extended coverage, higher throughput, less waiting time, and large-scale bandwidth connecting density [2], laying a way to connect hundreds of billion sensors between networks. As a result, uniform and heterogeneous sensor networks can be connected to largescale sensing devices, making great contributions to human beings provide advanced and intelligent services.
In recent years, with the gradual increase in the popularity of e-commerce and consumer consumption, domestic products have become only a part of consumers' buying wishes. More and more people have been attracted by the shopping list of cross-border e-commerce platforms. Highquality overseas products have driven the development of cross-border e-commerce (CBE) industry.

The cross-border e-commerce supply chain, with the help 5G IoT networks, becomes a value-added chain. The value of materials in the supply chain is increased due to processing, packaging, transportation, and tracking. Related companies in the logistics chain, information chain, and capital chain are getting benefit too. A complete e-commerce supply chain should include suppliers, manufacturers, distributors, retailers, and consumers, under the umbrella of an intelligent IoT platform.

The market changes rapidly, so the requirements passed to the supply chain will also change with the trends in the market, and the requirements of the supply chain are different at different stages of development. For example, in the initial stage, it is necessary to improve quality, reduce costs, and make products more competitive in the terminal; the 
initial stage requires the supply chain to fully release production capacity to ensure market supply; the market differentiation stage requires the supply chain to become more flexible and more and more flexible. It can adapt to the production of multiple varieties and small batches. Different from the company's business plan, the focus of supply chain performance should also be updated at any time.

In the literature, Kawa believes that e-commerce is one of the most dynamic and important sectors of economic activity [6]. The latest trend in the e-commerce market is crossborder trade, based on the sale of various products to customers in other countries. Kawa has conducted research on several problems in e-commerce, such as long time and high cost. The purpose of the research is to put forward the concept of a cross-border e-commerce integrator, which will solve the supply chain performance problems of crossborder e-commerce. For this reason, Kawa proposed the concept of a cross-border e-commerce integrator whose main task is to integrate the entire supply chain. Thanks to the economies of scale obtained by integrating the packages of many e-shops, integrators can achieve lower delivery costs in international transportation, return and exchange products more effectively, and better serve customers from different countries. This research method lacks theoretical and factual support and is not suitable for promotion in reality.

Prompanyo and Wang, instead, stated in [7] that the main purpose of his research is to verify the stability of the multiscale measurement of perceived value in the electronic loyalty model and explain the interrelationship between perceived values. In the context of cross-border e-commerce, they objectively evaluate the tradeoff of satisfaction and e-loyalty.

Prompanyo and Wang use confirmatory factor analysis and Bootstrap structural equation model to evaluate research hypotheses. The research results show that the multidimensional scale of perceived value can describe and explain the influence of perceived value on e-loyalty model. In this study, the overall perceived value positively and indirectly affects eloyalty through the mediation of network satisfaction. The process of this method is more complicated and error prone.

Turkulainen and Swink, alternatively, endeavored to evaluate the contextualized operation effects of cross-border e-commerce supply chain personnel (involving logistics and supply management) [8]. On the basis of the classic contingency theory, the research conducted a detailed contextual analysis of the performance impact of internal supply chain personnel participating in innovation activities. Specifically, Turkulainen and Swink believe that the impact of corporate product innovation activities on operational effectiveness is regulated by the organization's technical background, the level of integration of operating suppliers, and the interaction between these two factors. The research results show that, with the assistance of supplier integration, internal supply chain personnel in an organization can be a source or channel of valuable innovation-related knowledge, especially in a high-tech environment. In addition, since the complementary effects are highly dependent on the supply chain performance dimension, the results further support the argument for decomposing performance. Turkulainen and Swink discussed the effectiveness of supply chain personnel participat- ing in product innovation activities, by explaining the link mechanism between enterprise product innovation activities and performance, and established the basic relevance of supply chain personnel participating in product innovation activities. The research application cost is relatively high, and it is not suitable for popularization in practice.

Different from the existing work, this paper has the following contributions.

(1) It proposes the overall optimization inventory strategy of the supply chain through inventory adjustment, in a bid to improve the management of crossborder e-commerce supply chain

(2) It suggested a novel coordination model to optimize the performance of the cross-border e-commerce supply chain

(3) It takes into account the optimization of the efficiency of cross-border e-commerce supply chain

The remainder of the paper is organized as follows. Section 2 first proposes and formulates the CBE supply chain optimal management and coordination problem. Section 3 presents the detailed design of optimization and coordination schemes. Section 4 finally gives the numerical results of decision-making and coordination mechanism, followed by Section 5 to conclude the paper.

\section{Formulation of Optimal Management and Coordination Methods for CBE Supply Chain}

2.1. Big Data Mining Framework Based on $5 G$ Internet of Things. Big data mining is widely used in sensing regions and object processors. Compared to traditional data, there are multiple versions of big data generated in the $5 \mathrm{G}$ Internet of Everything, which requires more real-time analysis. Figure 1 illustrates that the $5 \mathrm{G}$ IoT data mining involves 3 steps, i.e., data collection, transmission, and then preprocessing. The data from fixed and mobile sensing areas may have distinct quality levels, and thus, preprocessing of the raw data needs to be done in the object processor.

2.2. Optimize Decision-Making through Inventory. Supply chain management should include supply chain planning, coordination and control, information flow and capital flow between participating organizations, and parts in the supply chain. Its purpose is to optimize the speed and certainty of all related programs and maximize all related programs. The net added value of the process improves the operational efficiency and efficiency of the organization [9]. An important part of the supply chain system is the research and analysis of the supply chain storage system. Generally speaking, in the sales process of $\mathrm{CBE}$, in order to meet the various needs of its customers in time, avoid shortages and delayed delivery. When things happen, it is necessary to hold a certain cost inventory [10]. Also, during the procurement and production period, in order not to interrupt the production process and maintain the continuity of production, cross-border ecommerce must have a certain amount of raw material 


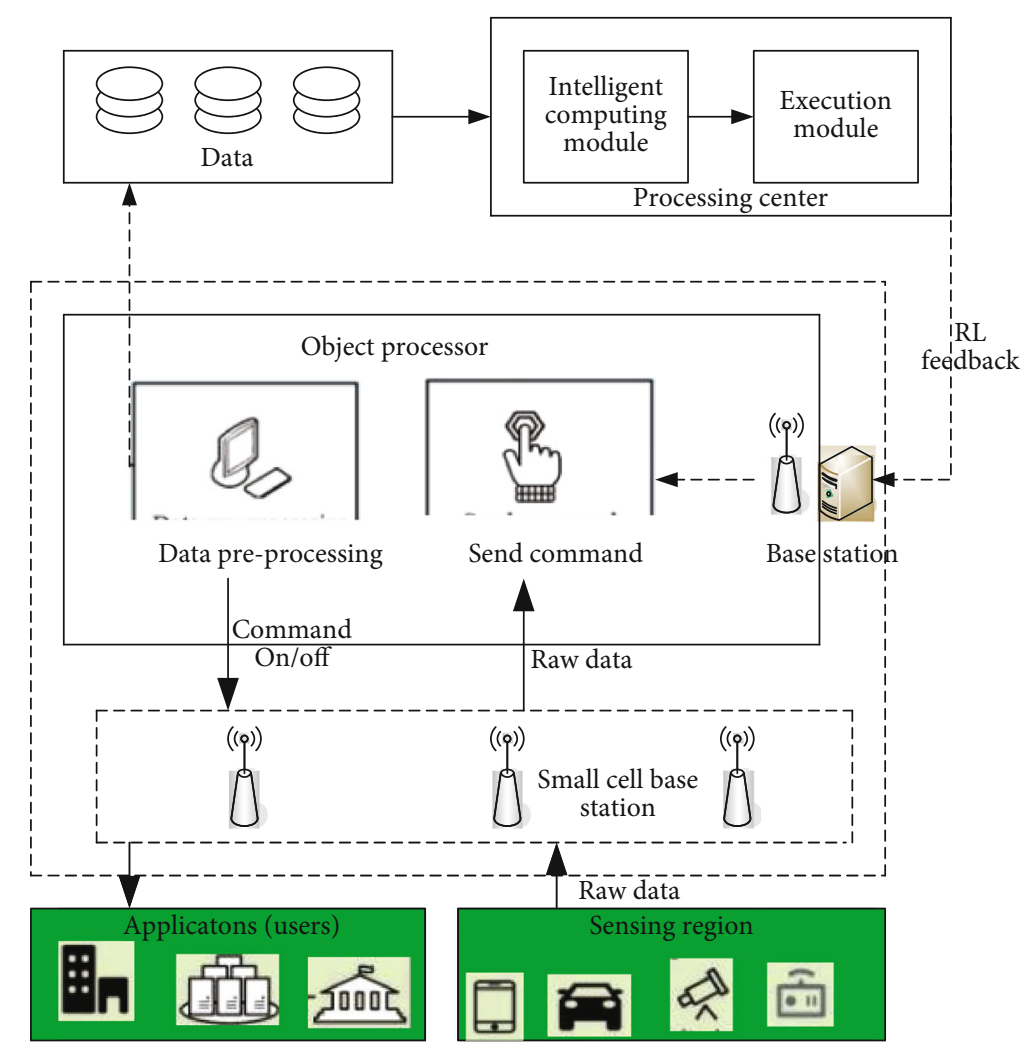

FIGURE 1: Big data mining framework.

inventory [11]. Due to many reasons, the amount of crossborder e-commerce inventory is often uncertain. If the inventory reserve is too small, it will not be able to meet the needs of customers. The excess reserve will not only occupy a large amount of funds, but also waste a lot of production area and inventory area, resulting in inventory backlog [12, 13]. Therefore, it is necessary to study how to determine a supply chain-oriented overall optimization inventory strategy through coordination. This problem must be comprehensively studied in order to achieve overall planning. It is usually necessary for sales, supply, production, finance, and other departments to work together to formulate a reasonable inventory quota, often revised and adjusted as the situation changes.

Assume that both the supplier and the demander adopt a periodic inspection strategy, that is, $(t, S)$ replenishment strategy [14]. This strategy refers to checking the inventory at regular intervals and placing an order to replenish the existing inventory to the maximum inventory level $S$. If the inventory is $I$ during the check, the order is $Q=S-I$. At the same time, it is assumed that the supply and demand parties adopt a one-to-many replenishment model, that is, the replenishment cycle of the distributor is an integer multiple of the retailer's replenishment cycle. In this way, it is possible to popularize and apply the inventory decision theory under the one-to-one replenishment model (that is, assuming that the replenishment cycle of both parties is the same) [15]. Suppose the entire planning period $H$ is divided into $n$ equal parts, the length of each equal part is $1=H / n$, and the replenishment time point $T_{m}=(i-1) H / n$ at the beginning of the $m^{\text {th }}$ period. According to the assumption, the retailer's demand per unit time is $f(t)$, so the demand from $T_{m}$ at the beginning of the $m^{\text {th }}$ period to time $t$ is $F_{m}(t)=$ $\sum_{x=T}^{t} f(x)$. Because the demand $f(x)$ obeys a normal distribution, it can be seen that $F_{m}(t)$ also obeys a normal distribution [16]. In practice, the customers that retailers face are general ones. In order to more accurately and effectively reflect the changes of customer demand over time, the unit time length of demand must be short. The time is regarded as a continuous variable in the hypothesis, in a bid to respond to customer demand in a timely manner [6]. As $F_{m}(t) \approx$ $\int_{T_{m}}^{t} f(x) d x$, the mean and variance of the demand are then calculated by $\mu_{F_{m}(t)}=\int_{T_{m}}^{t} \mu(x) d x, \sigma_{F_{m}(t)}^{2}=\int_{T_{m}}^{t} \sigma^{2}(x) d x$, respectively. When the retailer's demand $F_{m}(t)$ from the beginning of the $m^{\text {th }}$ period $T_{m}$ to time $t$ is lower than the basic inventory level $S_{k, m}$ at the beginning of the period, it is considered that the retailer will have inventory held at the time $t$ of the $m^{\text {th }}$ period, and its holding inventory is $S_{k, m}-F_{m}(t)$. When the retailer's demand $F_{m}(t)$ from the beginning of the $m^{\text {th }}$ period $T_{m}$ to time $t$ is higher than the basic inventory level $S_{k, m}$ at the beginning of the period, it is considered that the retailer is out of stock at the time $t$ of the $m^{\text {th }}$ period, and its out-of-stock quantity is $F_{m}(t)-S_{k, m}$ [9]. Both the out-of-stock quantity and the holding inventory are random processes. The average holding inventory of the retailer at time $t$ in the $m^{\text {th }}$ period is as follows: 


$$
E\left(S_{k, m}-F_{m}(t)\right)^{+}=\int_{0}^{s_{k m}}\left(S_{k, m}-x\right) \varphi_{F_{m}(t)}(x) d x
$$

Out of stock quantity is as follows:

$$
E\left(F_{m}(t)-s_{k, m}\right)^{+}=\int_{S_{k, m}}^{+\infty}\left(x-s_{k, m}\right) \varphi_{F_{m}(t)}(x) d x .
$$

The average inventory cost of the retailer in the $m^{\text {th }}$ period is as follows:

$$
\begin{aligned}
M C_{k, m}= & c_{k}+\int_{T_{m}}^{T_{m+1}} h_{k} E\left(S_{k, m}-F_{m}(t)\right)^{+} d t \\
& +\int_{T_{m}}^{T_{m+1}} p_{k} E\left(F_{m}(t)-S_{k, m}\right)^{+} d t .
\end{aligned}
$$

Substituting formula (1) and formula (2) into formula (3), a new relational expression can be obtained:

$$
\begin{aligned}
M C_{k, m}= & c_{k}+h_{k} \int_{0}^{S_{k, m}}\left(S_{k, m}-x\right) \int_{(m-1) 1}^{m l} \varphi_{F_{m}(t)}(x) d t d x \\
& +p_{k} \int_{S_{k, m}}^{+\infty}\left(x-S_{k, m}\right) \int_{(m-1) 1}^{m l} \varphi_{F_{m}(t)}(x) d t d x .
\end{aligned}
$$

From this, the retailer's inventory cost throughout the planning period has the following relationship:

$$
\begin{aligned}
M C_{k}= & n c_{k}+h_{k} \sum_{m=1}^{n} \int_{0}^{S_{k, m}}\left(S_{k, m}-x\right) \int_{(m-1) 1}^{m l} \varphi_{F_{m}(t)}(x) d t d x \\
& +p_{k} \sum_{m=1}^{n} \int_{S_{k, m}}^{+\infty}\left(x-s_{k, m}\right) \int_{(m-1) 1}^{m l} \varphi_{F_{m}(t)}(x) d t d x .
\end{aligned}
$$

The first term of the formula refers to the retailer's total order cost during the planning period, the second term refers to the retailer's total holding cost during the planning period, and the third term refers to the retailer's total out-of-stock penalty cost within $[17,18]$. In order to optimize the retailer's basic inventory level (formula (5)), the retailer's inventory cost can be derived with respect to $S_{k, m}$, and the following formula can be obtained:

$$
\begin{aligned}
\frac{\partial M C_{k}}{\partial S_{k, m}}= & h_{k} \int_{0}^{S_{k, m}} \int_{(m-1) 1}^{m l} \varphi_{F_{m}(t)}(x) d t d x \\
& -p_{k} \int_{S_{k, m}}^{+\infty} \int_{(m-1) 1}^{m l} \varphi_{F_{m}(t)}(x) d t d x \\
= & \left(h_{r}+p_{r}\right) \int_{(m-1) 1}^{m l} \int_{0}^{S_{k, m}} \varphi F_{m}(t)(x) d t d x-p_{k} 1 .
\end{aligned}
$$

Standardize the random variable $F_{m}(t)$ that obeys the normal distribution, let $F_{m}(t)-\mu_{F_{m}(t)} / \sigma_{F_{m}}(t)=Z$, and we know that the random variable $X$ also obeys the standard normal distribution [19]. Therefore, it can be seen that the values of random variable $F_{m}(t)$ and random variable $Z$ have the following relationship:

$$
\frac{x-\mu_{F_{m}(t)}}{\sigma_{F m(t)}}=Z \text {. }
$$

Substitute formula (7) into formula (6) to obtain a new relationship:

$$
\frac{\partial M C_{k}}{\partial S_{k, m}}=\left(h_{r}+p_{r}\right) \int_{(m-1) 1}^{m l} \phi\left(\frac{S_{k, m}-\mu_{F_{m}(t)}}{\sigma_{F_{m}(t)}}\right) d t-p_{k} 1 .
$$

Let formula (8) be equal to zero, and the optimal basic inventory level formula for retailers can be obtained as follows:

$$
\int_{(m-1) 1}^{m l} \phi\left(\frac{S_{k, m}-\mu_{F_{m}(t)}}{\sigma_{F_{m}(t)}}\right) d t=\frac{p_{k} 1}{h_{k}+p_{k}} .
$$

2.3. Adopt a Coordination Model of Cross-Border eCommerce Supply Chain Contracts. Since consumers' shopping experience is directly linked to the logistics service level of third-party logistics companies, it will have a certain impact on the business performance of cross-border ecommerce. Therefore, in order to encourage third-party logistics companies to make progress in the level of logistics services, cross-border e-commerce companies are willing to share a certain proportion of the cost for the third-party logistics companies in exchange for their own profits [20]. At the beginning of the period, a cross-border e-commerce company orders a certain product quantity $Q$ from a supplier based on market forecasts, pays the order fee $C_{1}$ and the inventory management $\cos t C_{2}$ of the self-built bonded warehouse, and determines the price of a certain product $p$ according to the market and cost: third-party logistics company. After understanding the market situation and a certain product type of the cross-border e-commerce company, when consumers place an order with the cross-border ecommerce company, the logistics service fee $P_{C}$ of the order is charged and the logistics service of the logistics service level $s$ is provided [21]. When the third-party logistics company incurs the cost of improving the logistics service level, the cross-border e-commerce company will voluntarily pay the part of the cost that accounts for $(1-\theta)(0<\theta<1)$ [22]. Based on this, the profit functions of cross-border ecommerce companies and third-party logistics companies are, respectively, as follows:

$$
\begin{aligned}
R_{1}= & \left(p-p_{C}\right) S(Q, s)-\left(c_{1}+c_{2}\right) Q-c_{e} I(Q, s) \\
& -c_{u} L(Q, s)-(1-\theta) g(s), \\
R_{2}= & \left(p_{C}-c_{C}\right) \times S(Q, s)-\theta g(s) .
\end{aligned}
$$

The warehouse in the bonded zone can be built into an imported logistics distribution center. According to the law, those warehouses can store foreign goods and enjoy the bonded policy. Therefore, foreign companies can be 


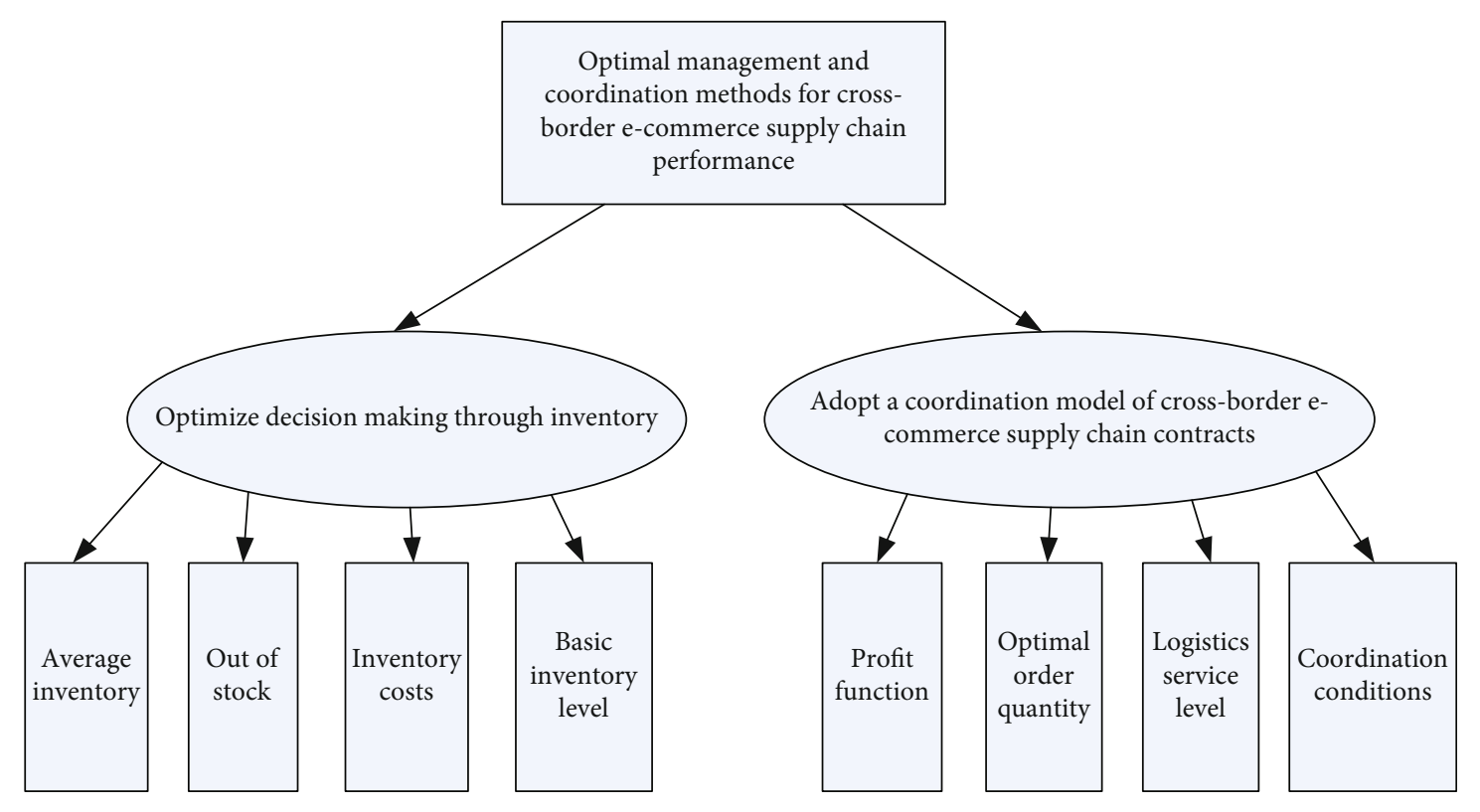

Figure 2: Part of the technical flow chart of this method.

organized to directly store the imported raw materials required by domestic enterprises in the bonded warehouse. When the company needs to import raw materials, purchasing at the warehouse in the bonded zone can form an overseas goods market within the country by build the bonded warehouse into an import logistics distribution center. Under the coordination of competition alliances, cross-border ecommerce companies and third-party logistics companies are still in the role of decentralized decision-making. The starting point is still to maximize their own interests. Crossborder e-commerce companies determine the optimal order quantity of goods, and third-party logistics company determines the optimal logistics service level in this situation [23]. The optimal order quantity of a product of a crossborder e-commerce company satisfies the following formula:

$$
Q_{1}=F^{-1}\left(\frac{p-p_{C}-c_{1}-c_{2}+c_{u}}{p-p_{C}+c_{e}+c_{u}}\right)-b p+d s
$$

The logistics service level $s_{2}$ of the third-party logistics company satisfies the following formula:

$$
s_{2}=\frac{d\left[(1-\varphi)\left(p-p_{C}+c_{e}+c_{u}\right)+p_{C}-c_{C}\right]}{\theta k} \times F(Q) .
$$

Substitute formula (13) into formula (12) to get a new relationship:

$$
\begin{aligned}
s_{2}= & \frac{d\left[(1-\varphi)\left(p-p_{C}+c_{e}+c_{u}\right)+p_{C}-c_{C}\right]}{\theta k} \\
& \times \frac{p-p_{C}-c_{1}-c_{2}+c_{u}}{p-p_{C}-c_{e}-c_{u}} .
\end{aligned}
$$

If a cross-border e-commerce company logistics service supply chain under a cost-sharing and revenue-sharing com- bination contract wants to achieve a coordinated state, it should meet $Q_{1}=Q^{*}, s_{2}=s^{*}$, and the relevant formulas should be combined to obtain the conditions for achieving supply chain performance coordination under the combined contract for

$$
p_{C}=(\theta+\varphi-1) p+(1-\theta) c_{C}+\theta c_{e}+\theta c_{u}
$$

In the cross-border e-commerce company's import cross-border e-commerce logistics service supply chain system based on the combination contract, the decision variables of the optimal order quantity $Q$ and logistics service level $s$ of a certain commodity are made by the cross-border e-commerce company and the third-party logistics company, respectively, decision [24]. To achieve the coordination of system decision-making, whether for $Q$ or $s$, the profit function of each member under the combined contract can be transformed into the affine function of $R_{0}(Q)$ and $R_{0}(s)$ under centralized decision-making, that is, $R_{1(Q)}=a R_{0}(Q)$ $+b$ (where $a$ and $b$ are independent of $Q$ constants).

The method part of this article uses the above methods to study the performance optimization management decisionmaking and coordination mechanism of cross-border ecommerce supply chain based on multiobjective optimization. Research is based on multiobjective optimization, cross-border e-commerce supply chain, performance management optimization, coordination mechanism, etc. The specific process is shown in Figure 2.

\section{Experiment Study on Management and Coordination of CBE Supply Chain}

3.1. Design a CBE Supply Chain Management Optimization Plan. Products and services are the core of each company's market competition. Optimizing supply chain performance 
can effectively reduce the operating costs of products in terms of manufacturing, transportation, and delivery, improve operating efficiency and market response speed, and enhance the company's service level. Supply chain optimization needs to start from the overall point of view to realize the harmonious symbiosis of upstream and downstream enterprises, reduce mutual internal friction, and improve the efficiency of the entire supply chain [25]. Optimize the general supply chain to achieve a fairer and more reasonable distribution of the benefits of each enterprise in the supply chain, better serve the end customers, and realize the value of the entire supply chain. Through optimization, an efficient and streamlined supply chain must be established to improve the competitiveness of cross-border e-commerce companies in the market; and links that are not suitable for improving the supply chain efficiency of cross-border e-commerce companies and waste corporate resources should be adjusted [26].

(1) Principles of supply chain performance optimization

(1) Fully Identify and Meet Consumer Needs. Supply chain management realizes the process of products from satisfying consumer needs to product design, production, processing, packaging, logistics warehousing, and distribution [27]. Products that meet consumer needs are the value transfer process of a successful supply chain, and the follow-up part is a necessary process to realize this value transfer.

(2) Shorten the Product Supply Chain Cycle. The product supply chain cycle is the entire process of product design, production, and sales to consumers. If the supply cycle is too long, it will be at a disadvantage in a rapidly changing market [28]. Shortening the product supply chain cycle can shorten the time from product development, procurement to customer feedback, and make companies more competitive.

(3) Shorten the Testing Time of New Products. For cross-border e-commerce platforms, from product selection, promotion, to consumer feedback data analysis, to feedback to suppliers, bulk purchase, production and logistics transportation to mass sales, a certain timeliness is required [29]. It is possible to use methods such as manual intervention and social marketing inside and outside the platform to quickly implement new product evaluation and promotion and obtain customer feedback as soon as possible to respond to market changes quickly.

(4) Reduce Supply Chain Operating Costs. Supply chain operating cost is the necessary cost from the production of a company's products to the sales process [30]. Operating costs will ultimately be reflected in product sales prices and profits, and reducing supply chain operating costs will help companies better control profits, give prod- uct sales prices more room for adjustment, and improve product competitiveness in the market.

(5) We are not afraid of more scenes, but the scenes should not be specifically customized. If it is too customized and cannot be copied, the cost will be high and the business will fail. We have to respond to the needs of customers and use general multiscenario solutions to digest customer requirements and resolve their problems

\section{(2) Design optimization steps}

According to the general idea and principle of optimization, in order to achieve better results, the following steps need to be optimized.

First of all, there are more or less problems in each link in the supply chain. Enterprises need to start from the appearance of the problem, find the essence of the problem, and analyze the connection between the problem and the problem in each link [31].

Secondly, starting from the essence of the problem, combining the value and development of the entire chain, give the most suitable but not the optimal solution, so that the problems in each link can be comprehensively solved, the cost can be controlled, and the process can be executed. The result is satisfactory [32].

Then, after the plan comes out, there must be a dedicated person in charge to supervise the implementation of the plan and implement feedback during the implementation of the plan. If the expected effect cannot be achieved, the plan needs to be optimized. During the implementation of the optimization plan, the plan needs to be tracked in time. For the relevant implementation situation, it is necessary to analyze and solve the new factors that affect the resolution of the problem in a timely manner [33].

Finally, after the implementation of the entire program is completed, the corresponding evaluation system is used to evaluate and score the effect of the program to ensure that the company has both input and output for each program implementation. Do a good job in the production and sorting of text materials and data materials and record and sort the problems and points that can be improved during the implementation of the plan and expand the company's experience database for further improvements in the future optimization plan.

\subsection{Realize Cross-Border e-Commerce Supply Chain} Performance Optimization. Sort out the business processes of existing companies importing cross-border e-commerce, sort out suitable business processes and system processes, and rely on advanced information technology to establish an operating mechanism and an efficient IT management system that can quickly support new business expansion. At the same time, through the reconstruction of the existing business process, the customs clearance business is serviceoriented to provide support for upstream businesses, and at the same time, the business that is not related to customs clearance is separated from the system, such as "accepting orders, docking with warehouse systems, and docking with 
TABLE 1: Cross-border e-commerce business process.

\begin{tabular}{lcccc}
\hline Step & 1 & 2 & 3 & \\
Process node & Order node & Transfer node & Check joints & Parcel production node \\
Step & 5 & 6 & 1 & 9 \\
Process node & $\begin{array}{c}\text { Outbound declaration } \\
\text { and loading node }\end{array}$ & Loading declaration node & Delivery distribution node & Delivery node \\
\hline
\end{tabular}

e-commerce platforms." Establish a reasonable business system, maintain the purity of production, and reduce the complexity of the production system. Establish an order management system to conduct unified, standardized, and precise control of cross-border e-commerce and general trade orders. Establish a three-dimensional production, operation, and maintenance monitoring system for product service level, timeliness assessment, and KPI assessment to create an efficient service platform.

Receive sales orders from major platforms. When receiving orders, the system needs to perform data verification. After the verification is passed, the corresponding platform will be notified whether the order is successfully received. When receiving the order, the relevant data that need to be verified for legality are sorted out so that the system can promptly remind. After the order is successfully received, the system needs to determine whether the order meets the production requirements. It needs to check the goods, merchants, and inventory. When the order is successfully transferred, it needs to inform the platform that the order has been successfully received and the production is in progress; then, the customs and the customs clearance and declaration work of the national inspection system include the issuance of declaration work orders, the issuance of three declaration instructions (orders, waybills, and payment orders), three declaration receipt processing, list declaration instructions issuance and list declaration receipt processing, and customs clearance. After the completion, the package production can be arranged; the order will be delivered to the warehouse for production after customs clearance is completed, and the packaging of the entire order will be completed. The package production node mainly includes order distribution, wave generation, product picking, order picking, and order packaging. After the production of the order package is completed, before loading the corresponding order on the truck, you need to complete the customs declaration activities of the order from the warehouse. After the declaration is completed, you can load the corresponding order on the truck and leave the bonded area; when the order is loaded, the final declaration is required, that is, the customs inspection order is about to leave the bonded area to complete the order delivery process. When the order loading declaration is completed, you can leave the bonded area and deliver it to the domestic logistics distributor; when the order loading declaration is completed and the truck leaves the bonded area, the order needs to be handed over to the corresponding distributor to start domestic delivery. The entire link needs system and physical handover with logistics distributors; when the distributor receives the package, it completes domestic distribution according to the scheduled route, and the logistics dis- tributor needs to return real-time logistics distribution information to the e-commerce platform and the logistics tracking system of the enterprise. After the parcel is delivered to the customer, the customer will sign for the receipt. At this time, the customer's receipt information will be sent back to the e-commerce platform and the enterprise's logistics tracking system to complete the overall business process of crossborder e-commerce. Draw this cross-border e-commerce business process into a table, as shown in Table 1.

Through the abovementioned business sorting and process standardization, the main process of the entire cross-border e-commerce import business is clarified, and then, by combining this process, relevant cross-border ecommerce companies can design the overall business system to meet the smooth development of the abovementioned business.

\subsection{Realize Cross-Border e-Commerce Logistics Management Optimization}

\section{(1) Innovative logistics distribution model}

At present, there are two innovative distribution models for cross-border e-commerce logistics, namely, logistics outsourcing and the establishment of multinational e-commerce logistics cooperation alliances. Traditional cross-border ecommerce logistics and distribution include three types: the overseas direct mail mode that sells goods to consumers by means of postal parcels, commercial express, or logistics lines, and this method is generally expensive, and by means of bonded areas and free trade zones. Stocking mode: this mode has certain requirements for inventory estimation; self-built overseas warehousing mode: but the overseas warehousing construction cost is high and the cycle is long.

(1) For many small and medium-sized cross-border ecommerce companies that cannot afford high logistics costs, they can use logistics outsourcing: the first typical logistics outsourcing method is third-party logistics, assisted by self-operated distribution models, and remote areas are selected postal services; the second is the fourth-party logistics, which provides logistics planning, consulting, and supply chain management activities for both parties and third parties. It integrates resources from domestic and foreign merchants and logistics companies and integrates them on the website through Internet information technology. For consumers to choose the best solution, the fourth-party logistics e-commerce platform can also carry out unified customs declaration 
TABLE 2: Major global cross-border e-commerce platforms.

\begin{tabular}{|c|c|c|c|}
\hline Nation & North America & Europe & South America \\
\hline $\begin{array}{l}\text { Electronic business } \\
\text { platform }\end{array}$ & $\begin{array}{l}\text { Amazon, Bonanza, Cratejoy, eBay, } \\
\text { Etsy, Jet, Newegg, Reverb, Walmart, } \\
\text { Wayfair, Wish, Zibbet }\end{array}$ & $\begin{array}{l}\text { Allegro, Asos. Cdiscount, Cel. } \\
\text { DaWanda.Emag. Flubit, Fnac. } \\
\text { Fruugo, Game. Mobile.de. Okazii, } \\
\text { OnBuy, PriceMinister. Real.de, } \\
\text { Tesco. Zalando, Otto }\end{array}$ & $\begin{array}{l}\text { Americanas, Casas Bahia, } \\
\text { Dafiti, Extra, Linio, } \\
\text { Mercado Libre. Submarino }\end{array}$ \\
\hline Number of platforms & 12 & 18 & 7 \\
\hline Nation & Asia & Africa & Oceania \\
\hline $\begin{array}{l}\text { Electronic business } \\
\text { platform }\end{array}$ & $\begin{array}{l}\text { Alibaba, AliExpress, Flipkart, GittiGidiyor, } \\
\text { HipVan, JD, Kaola, Lazada, Qoo10, Lotte. } \\
\text { Shopee, Snapdeal, Souq, TaoBao, tmall. vip }\end{array}$ & Jumia, Kilimall, Konga & Iconic.MyDeal \\
\hline Number of platforms & 16 & 3 & 2 \\
\hline
\end{tabular}

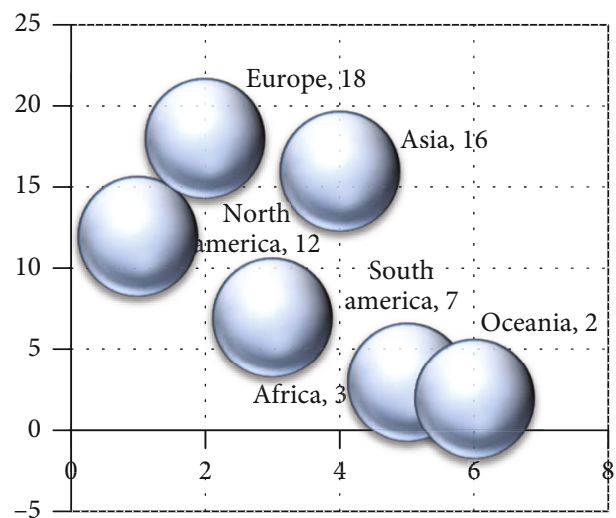

Figure 3: Major global cross-border e-commerce platforms

for cross-border e-commerce companies, pay taxes on their behalf, and conduct centralized commodity inspection reviews

(2) Establish a multinational e-commerce logistics cooperation alliance. The logistics cooperation alliance is a logistics model in addition to self-operated logistics, third-party and fourth-party logistics. It refers to two or more companies that are formed on the basis of benefit-sharing with other companies in order to make up for their own logistics

(3) Competitiveness. Joint Action and Partnership. China's first cross-border e-commerce cooperation alliance was established in Lanzhou in January 2016. After its establishment, the alliance integrated international railway freight trains and the ecommerce resources of various countries to form a smooth and efficient logistics channel, which also gave cross-border e-commerce the future development direction of the logistics of commercial and import enterprises has pointed the way.

(2) Improve the logistics guarantee mechanism

First, invest in the construction of a reverse logistics information tracking system. An efficient and complete
TABLE 3: Development of cross-border e-commerce in the past five years.

\begin{tabular}{lcc}
\hline Age & Transaction amount (unit: trillion) & Growth rate \\
\hline 2015 & 5.47 & $30.24 \%$ \\
2016 & 6.72 & $22.85 \%$ \\
2017 & 8.06 & $19.94 \%$ \\
2018 & 9.12 & $13.15 \%$ \\
2019 & 10.31 & $19.44 \%$ \\
\hline
\end{tabular}

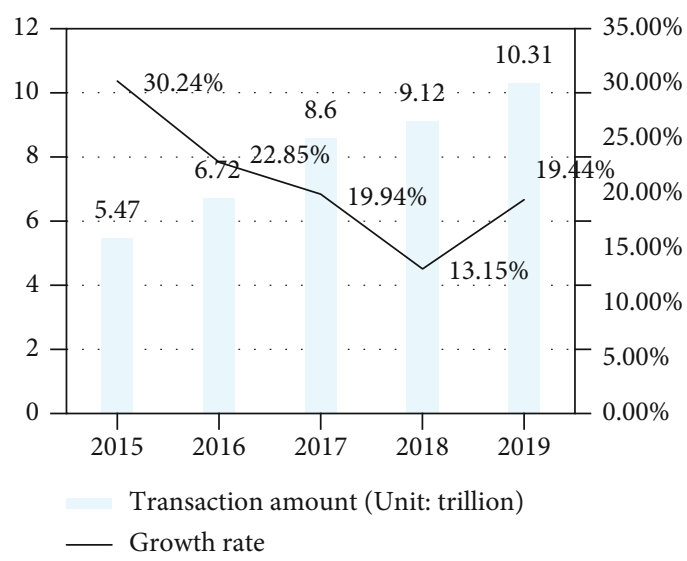

Figure 4: Development of cross-border e-commerce in the past five years.

reverse logistics information system should be able to integrate the information of each node member of the supply chain. Through this system, cross-border e-commerce import companies can know the user ID of reverse logistics the reason for return and the cost; logistics companies can find the location, time, and quantity of the returned goods; foreign suppliers can trace the origin to the production place and supply channels of the product for continuous attention; users can estimate the cost and processing time of the return. The reverse logistics system requires enterprises to arrange and combine all information to form a database and apply it to the operation of the enterprise. Enterprises can use this 
TABLe 4: Distribution of cross-border e-commerce companies.

\begin{tabular}{|c|c|c|c|c|c|c|c|}
\hline Area & Beijing & Shanghai & Guangdong & Zhejiang & Jiangsu & Other areas & Nationwide \\
\hline Number of cross-border e-commerce companies & 238 & 326 & 4229 & 1746 & 703 & 6041 & 13,283 \\
\hline Percentage & $1.79 \%$ & $2.45 \%$ & $31.84 \%$ & $13.14 \%$ & $5.29 \%$ & $45.48 \%$ & 1 \\
\hline
\end{tabular}

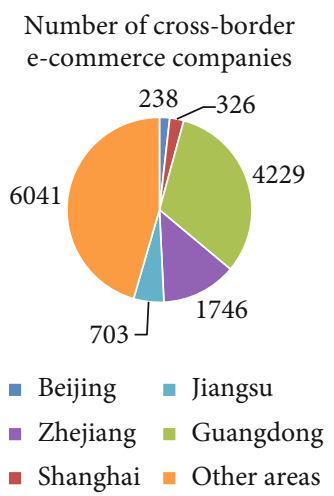

Figure 5: Distribution of cross-border e-commerce companies.

system to deal with consumer returns and exchanges in time based on database information.

Second, improve the online purchase process. Ecommerce companies or platforms should first provide product information as much as possible in the online store. Even if the customer has placed an order and paid, if you want to cancel the order and refund, the customer service staff should deal with it as soon as possible after asking the original situation to reduce unnecessary delivery. Costs reduce the return rate. At the same time, companies should collect, analyze, and summarize relevant information about returned goods, find out possible problems with returned goods, and optimize management methods to reduce the return rate in response to these problems.

\section{Decision-Making and Coordination Mechanism Analysis}

\subsection{Macroenvironment Analysis of Cross-Border e-Commerce Business}

(1) Political environment

With the rapid development of globalization, cooperation between countries is becoming more and more close. China's "one belt, one road" policy is launched on this basis, which is also an important project for our country to go abroad. Since the one belt, one road one belt, one road has been signed. We have signed the development agreement with more than 30 countries along the way. The main form of cooperation is e-commerce cooperation. e-commerce has also become an important part of the "one belt and one way" development cooperation, playing a key role in the economic and trade cooperation between our country and other countries. Another relevant research shows that the main form of global economic and trade cooperation is ecommerce. Currently, there are 58 major e-commerce plat- forms in the world. Cross-border e-commerce is an important part of it. The details are shown in Table 2 and Figure 3.

As can be seen from the chart, Europe has the most ecommerce platforms and the most mature development, with a total of 18 e-commerce platforms, followed by China, with a total of 16 e-commerce platforms, of which Taobao is the most famous; North America is ranked third in the number of e-commerce platforms. The most famous of which is the Amazon e-commerce platform. Although China's ecommerce platform and cross-border e-commerce business have started slowly, they have developed rapidly and often set new transaction records at the end of each year.

\section{(2) Economic environment}

As the world's second-largest economy, although China's economic growth has slowed in recent years, its economic growth still ranks first in the world. The form of China's imports and exports has risen steadily. With the rapid development of China's cross-border e-commerce industry, more and more SMEs and individuals have joined the cross-border e-commerce industry, which has accelerated the development of the industry. At the same time, the rise of domestic production costs has also accelerated the transformation of the industry, and the mode of foreign trade has gradually shifted to the online. Under this situation, cross-border ecommerce platforms are developing rapidly, and at the same time, the competition among cross-border e-commerce companies has increased unprecedentedly. According to China Customs statistics, in 2019, China's total import and export trade amounted to 31.86 billion yuan, an average annual growth rate of $21 \%$. According to the latest statistics from iResearch, the scale of China's cross-border e-commerce reached 94.1 billion yuan in 2019, a year-on-year increase of $22.7 \%$ and a growth rate of $29.41 \%$. Based on the calculation of these previous data, Ali believes that the transaction volume of China's cross-border e-commerce will rise to 13.15 trillion in 2020, and the growth rate will reach 1.35 trillion $28.52 \%$, a growth rate of $39.1 \%$. The future crossborder development of e-commerce has a huge market. Draw the specific situation into a chart, as shown in Table 3 and Figure 4.

The report shows that in terms of cross-border ecommerce model structure, cross-border e-commerce B2B represents 83 companies. In 2018, China's cross-border ecommerce accounted for $2 \%$, and cross-border e-commerce transaction $\mathrm{B} 2 \mathrm{C}$ accounted for $16.8 \%$. The $\mathrm{B} 2 \mathrm{~B}$ model accounts for more than $80 \%$ of cross-border e-commerce models and has been the dominant business model for many years. The business model of cross-border e-commerce B2B lies in disintermediation, allowing owners and product names to communicate directly and dealing with producers 
TABLE 5: Cost comparison before and after implementation of cross-border e-commerce supply chain optimization plan.

\begin{tabular}{lcc}
\hline Project & Before implementation & After implementation \\
\hline Commodity purchase cost & 82.00 & 82.00 \\
International freight+port fees & 7.04 & 7.04 \\
Tariff & 7.05 & $/$ \\
Value-added tax & 14.78 & $/$ \\
Comprehensive cross-border e-commerce tax & $/$ & 13.31 \\
Packaging supplies & 0.80 & 0.80 \\
Cross-border warehouse distribution service fee & $/$ & 15.00 \\
Guangzhou warehouse storage & 3.80 & $/$ \\
Domestic express delivery & 12.13 & $/$ \\
Sales loss & 1.76 & 1.76 \\
Profit & 8.23 & 8.23 \\
Selling price & 137.56 & 125.74 \\
\hline
\end{tabular}

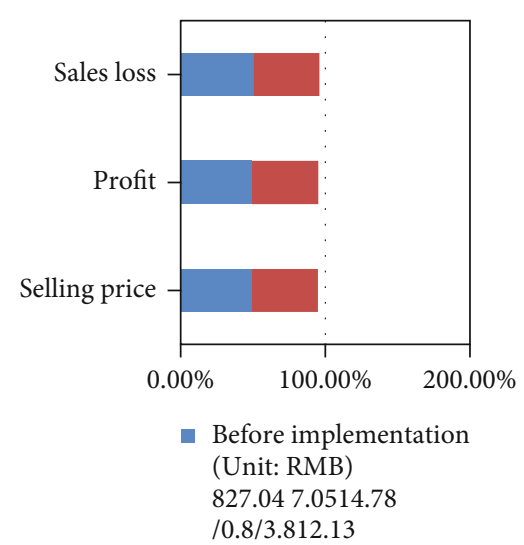

FIGURE 6: Cost comparison before and after implementation of cross-border e-commerce supply chain optimization plan.

and trademarks. More and more B2C cross-border ecommerce platforms have been established.

Factories and consumers are directly connected to many Internet networks, reducing trade links and eliminating information asymmetry in the form of B2B2C. The B2C model is more flexible than traditional foreign trade and other forms.

\section{(3) Social environment}

In today's economic globalization, the rapid development of the Internet has accelerated the exchange of the world. The globalization of economy and commodity has made the dependence between countries closer and has brought into play the advantages of various countries and promoted their consumption and development. With the smooth flow of consumption channels in various countries, products with personal characteristics and preferences are more favored by people. Cross-border e-commerce provides them with shopping channels, enabling them to purchase their favorite products through cross-border e-commerce. Therefore, cross-border e-commerce has entered the era of take-off. With the development of network culture, consumers have more ways to understand foreign brand culture and at the same time purchase a large number of foreign goods through cross-border shopping, and this process continues to promote the spread and reputation of foreign brands in China. To promote the rapid growth of imported e-commerce, cross-border e-commerce promotes a new round of consumption upgrades in China and becomes a new driving force for the sustained growth of China's national economy. For enterprises, it is necessary to seize this opportunity and make good use of the Internet platform to achieve a winwin situation for enterprises and consumers. The rapid development of cross-border e-commerce has benefited from the rapid development of Internet technology. The Internet is a "catalyst" for the development of cross-border e-commerce. The rapid development of the Internet, big data, and information technology has shortened. With the development of mobile information technology and the change of people's past communication modes, consumers can obtain market information more efficiently and quickly. The development of informatization in the warehousing and logistics industries ensures that consumers can obtain dynamic information about commodities. Real-time control and the improvement of diversified payment methods and security technology guarantee consumer safety. The development of science and technology has provided a solid foundation and guarantee for cross-border e-commerce. According to the search results of Tianyan Check, there are a total of 13,283 formal enterprises specializing in cross-border e-commerce across the country, which are located in major cities or small and medium-sized cities in China. The specific conditions are shown in Table 4 and Figure 5.

According to statistics, most of China's formal enterprises specializing in cross-border e-commerce are located in Zhejiang Province, where Alibaba was founded. The rest are mostly located in developed areas such as Beijing and Shanghai. There are few cross-border e-commerce-related companies in the western region. It can be seen that in order to optimize the performance of cross-border e-commerce supply chain management, decision-making, and coordination, at least the company should be located in a convenient transportation and economically developed area. 
TABLE 6: Results of scale reliability analysis.

\begin{tabular}{lccc}
\hline Dimension & Cronbach's alpha & Number of items & Dimension \\
\hline Supply chain management capabilities & 0.803 & 7 & Supply chain management capabilities \\
Online marketing & 0.821 & 5 & Online marketing \\
Inventory management & 0.842 & 5 & Inventory management \\
Brand management & 0.887 & 5 & Brand management \\
Representation & 0.846 & 9 & Representation \\
\hline
\end{tabular}

4.2. Evaluation and Analysis of Cost Optimization of CrossBorder e-Commerce Supply Chain Optimization Plan. The cost composition of cross-border imported goods include procurement costs, international logistics, import customs clearance and taxation, warehousing, packaging, domestic logistics, and sales loss. Take a well-known cross-border ecommerce company as an example. Before the optimization, the company's business model was to import through general trade, pay tariffs+value-added tax normally, store goods in Guangzhou's own warehouses, and deliver goods from Guangzhou warehouses to all parts of the country. After the implementation of the supply chain optimization plan, the company's business model was adjusted to stock up through the cross-border e-commerce comprehensive experimental zone supervision library, and the import of goods paid cross-border e-commerce comprehensive tax, and the third-party logistics company was responsible for the implementation of "warehouse and distribution integration" warehousing and delivery of goods. The cost composition comparison before and after the implementation of the company's cross-border e-commerce supply chain optimization plan is shown in Table 5 and Figure 6.

Under the same conditions, the sales price of the company's cross-border supply chain optimization plan is reduced by $8.59 \%$ compared to before implementation. The total tax on cross-border e-commerce is equal to $69 \%$ of the tax. The domestic adjusted tax rate is calculated based on the general business model and the increased tax rate. After the adjustment, the cost reduction rate is greatly reduced. The supply of the latest e-commerce service is $14 \%$ higher than the previous domestic price, but after replacing the storage fee of the Guangzhou warehouse, the distribution cost of the warehouse has been reduced by about $11 \%$. At the same time, storage and distribution links are entirely third parties, which greatly reduce the company's hidden management costs for storage and distribution links.

4.3. Reliability Test Analysis of Cross-Border e-Commerce Supply Chain Optimization Decision Model. The degree of reliability plays a critical role in measuring the consistency level of the results achieved by a specific approach. In particular, the credibility of internal cohesion mainly relies on Cronbach's alpha factor to test the consistency of responses to all elements on the same scale. Table 6 and Figure 7 demonstrate our analysis using the above criterion.

The reliability analysis part is to take the reliability factor (Cronbach $\beta$ ) according to the problems of each level to understand the consistency of the model rating. In this paper, the Cronbach $\beta$ value of each scale factor of the optimized

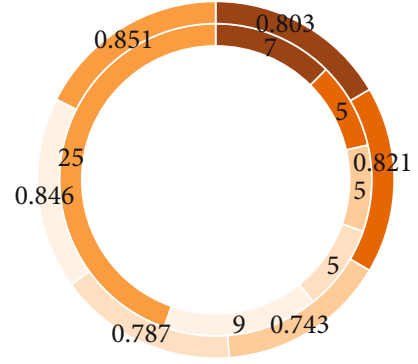

$$
\begin{aligned}
& \text { Supply chain } \\
& \text { management capabilities } \\
& \text { Online marketing } \\
& \text { Inventory management } \\
& \text { Brand management } \\
& \text { Representation } \\
& \text { Whole sample }
\end{aligned}
$$

FIGURE 7: Results of scale reliability analysis.

decision model is greater than 0.80 . From a statistical point of view, the reliability coefficient of any test or scale is above 0.80 , indicating that the internal consistency of the test or scale is good. This shows that the optimized decision-making coordination mechanism has high internal consistency.

\section{Conclusion}

The advent of 5G and IoT has changed people's lifestyles and promoted the creation of new business models. As a product of the Internet era, cross-border e-commerce is a concrete manifestation of "Internet + foreign trade". In recent years, it has developed rapidly. There are more and more traditional foreign trade companies, especially small and medium foreign trade companies, and they have begun to transform into a cross-border e-commerce model. In this process, companies urgently need to optimize and upgrade the original traditional international supply chain system to cover the needs of the global cross-border e-commerce industry.

In the early stage of the research, this paper puts forward the optimization management and coordination method of cross-border e-commerce supply chain performance. To determine the overall optimized inventory strategy oriented by the supply chain through inventory coordination has become an important means of cross-border e-commerce supply chain performance management; adopting the coordination model of cross-border e-commerce supply chain contracts, in order to encourage third-party logistics companies to improve in terms of logistics service levels, cross-border e-commerce 
companies are willing to share a certain proportion of the cost for third-party logistics companies in exchange for their own profits. This paper also proposes to design a cross-border e-commerce supply chain performance management optimization plan, to achieve cross-border e-commerce supply chain performance optimization, and to achieve crossborder e-commerce logistics management optimization.

Justified by the numerical results, this article conducts comprehensive analysis. We conclude that although China's e-commerce platform and cross-border e-commerce business have started slowly, they have developed rapidly, and the transaction volume record is often refreshed at the end of each year; the performance of the cross-border ecommerce supply chain must be improved. To optimize management decision-making and coordination, at least try to locate the company in an area with convenient transportation and developed economy. Finally, it is clear that our decision model pushes the Cronbach's alpha factor of all dimensions greater than 0.80 , indicating a high internal consistency with coordination mechanism.

\section{Data Availability}

The data used in this article is the company's private data.

\section{Conflicts of Interest}

The authors declare that they have no conflicts of interest.

\section{Acknowledgments}

This study was supported by the National social science major project in 2017 "Research on reform and innovation of supervision system of state owned enterprises" (17ZDA087).

\section{References}

[1] A. Whitmore, A. Agarwal, and L. Da Xu, "The Internet of Things - a survey of topics and trends," Info. Systems Frontiers, vol. 17, no. 2, pp. 261-274, 2015.

[2] M. Agiwal, A. Roy, and N. Saxena, "Next generation 5G wireless networks: a comprehensive survey," IEEE Communications Surveys \& Tutorials, vol. 18, pp. 1617-1655, 2017.

[3] L. Atzori, A. Iera, and G. Morabito, "Understanding the Internet of Things: definition, potentials, and societal role of a fast evolving paradigm," Ad Hoc Networks, vol. 56, pp. 122-140, 2017.

[4] S. H. Shah and I. Yaqoob, “A survey: Internet of Things (IOT) technologies, applications and challenges," in 2016 IEEE Smart Energy Grid Engineering (SEGE), pp. 381-385, 2016.

[5] X. Du, M. Guizani, Y. Xiao, and H.-H. Chen, "Routing-driven elliptic curve cryptography based key management scheme for heterogeneous sensor networks," IEEE Transactions on Wireless Communications, vol. 8, no. 3, pp. 1223-1229, 2009.

[6] A. Kawa and W. Zdrenka, "Conception of integrator in crossborder E- commerce," Logforum, vol. 12, no. 121, pp. 63-73, 2016.

[7] M. Prompanyo and L. Wang, "A validation of the multidimensional perceived value in the model of E-loyalty towards Sino-
Thai cross- border E-commerce based on China s customers," Journal of Business Research-Turk, vol. 12, no. 2, pp. 10141022, 2020.

[8] V. Turkulainen and M. L. Swink, "Supply chain personnel as knowledge resources for innovation-a contingency view," Journal of Supply Chain Management, vol. 53, no. 3, pp. 4159, 2017.

[9] B. Lu and H. Wang, "Research on the competitive strategy of cross-border E-commerce comprehensive pilot area based on the spatial competition," Scientific Programming, vol. 2016, no. 1, 2016.

[10] M. A. A. Aqlan, "Research on the status quo and countermeasures of cross-border E-commerce development in Arab countries," Open Journal of Business and Management, vol. 8, no. 4, pp. 1536-1542, 2020.

[11] S. Ji, X. Wang, W. Zhao, and D. Guo, "An application of a three-stage XGBoost-based model to sales forecasting of a cross-border E-commerce enterprise," Mathematical Problems in Engineering, vol. 2019, no. 2, 2019.

[12] S. Ji, "Research on personalized recommendation algorithm of cross- border e-commerce under large data background," Italian Journal of Pure and Applied Mathematics, vol. 41, pp. 358368, 2019.

[13] J. Mou, Y. Cui, and K. Kurcz, “Trust, risk and alternative website quality in B-buyer acceptance of cross-border E-commerce," Journal of Global Information Management, vol. 28, no. 1, pp. 167-188, 2020.

[14] L. Shi, S. Liu, and S. Petrovi, "Cryptanalysis of a pseudorandom generator for cross-border E-commerce," Ingénierie des systèmes d information, vol. 24, no. 4, pp. 361-365, 2019.

[15] P. Wang, "On the development of cross-border E-commerce and the transformation of foreign trade model," Modern Economy, vol. 9, no. 10, pp. 1665-1671, 2018.

[16] K. Gao, Y. Huo, and Y. Liu, "An investment decision-making research on cross-border e-commerce overseas warehouse based on real option," ICIC Express Letters, vol. 11, no. 5, pp. 1005-1010, 2017.

[17] A. J. Lin, E. Y. Li, and S. Y. Lee, "Dysfunctional customer behavior in cross-border E-commerce: a justice-affectbehavior model," Journal of Electronic Commerce Research, vol. 19, no. 1, pp. 36-54, 2018.

[18] Y. Fang, "Current situation, obstacles and solutions to China's cross-border E-commerce," Open Journal of Social ences, vol. 5, no. 10, pp. 343-351, 2017.

[19] Y. K. Wang, "Model for evaluating the logistics service quality of cross-border E-commerce enterprises with intuitionistic fuzzy information," Journal of Computational and Theoretical Nanoence, vol. 14, no. 2, pp. 1136-1139, 2017.

[20] L. Yang, J. Chen, H. Zhang, H. Jiang, S. A. Vorobyov, and D. T. Ngo, "Cooperative wireless multicast: performance analysis and time allocation," IEEE Transactions on Vehicular Technology, vol. 65, no. 7, pp. 5810-5819, 2016.

[21] E. Chancey, J. L. M. Flores, and M. B. Palma, "Redesign of the supply chain of a restaurant franchise in the food industry," Global Journal of Business Research, vol. 10, no. 2, pp. 103111, 2016.

[22] D. D. Zulfikar and D. Ernawati, "Pengukuran kinerja supply chain menggunakan metode green score DI PT," XYZ. JUMINTEN, vol. 1, no. 1, pp. 12-23, 2020.

[23] G. Efrem, W. C. Mariam, A. Jemal, and H. Assefa, “Assessment of laboratory commodity supply chain system at public health 
facilities of Jimma zone and Jimma town administration, south west Ethiopia," International Journal of Research-GRANTHAALAYAH, vol. 7, no. 10, pp. 471-490, 2019.

[24] K. Anindita, I. G. A. A. Ambarawati, and R. K. Dewi, "Kinerja rantai pasok di pabrik gula madukismo dengan metode supply chain operation reference-analytical hierarchy process (SCOR-AHP)," Agrisocionomics Jurnal Sosial Ekonomi Pertanian, vol. 4, no. 1, pp. 125-134, 2020.

[25] A. K. Joshi, I. A. Dandekar, and A. P. Shrotri, "Efforts taken by Indian administrative systems to manage the supply chain of essential commodities during the lockdown period of COVID-19-a case study," Journal of Information and Computational ence, vol. 10, no. 4, pp. 804-811, 2020.

[26] M. Shafiq, A. Akhtar, and A. H. Tahir, "A systematic review of efficiency and effectiveness in humanitarian organizations logistics and supply chain management (1995-2019)," in Hamdard Islamicus: quarterly journal of the Hamdard National Foundation, vol. 43no. 1, pp. 655-706, Pakistan, 2020.

[27] T. A. Bui, H. T. T. Trinh, and B. T. Nguyen, “The potential for Tra Vinh province to become trade gateway of the Mekong Delta from logistics and supply chainmanagement perspectives," entific Journal of Tra Vinh University, vol. 1, no. 4, pp. 23-40, 2020.

[28] M. Ju and I. M. Kim, "ML performance analysis of the decodeand-forward protocol in cooperative diversity networks," IEEE Transactions on Wireless Communications, vol. 8, no. 7, pp. 3855-3867, 2019.

[29] L. Dwyer, T. Armenski, and L. K. Cvelbar, "Modified importance-performance analysis for evaluating tourism businesses strategies: comparison of Slovenia and Serbia," International Journal of Tourism Research, vol. 18, no. 4, pp. 41-75, 2016.

[30] W. Schulz, G. Diendorfer, and S. Pedeboy, "The European lightning location system EUCLID - Part 1: performance analysis and validation," Natural Hazards and Earth System Sciences, vol. 16, no. 2, pp. 595-605, 2016.

[31] E. Frauman and S. Banks, "Gateway community resident perceptions of tourism development: incorporating importanceperformance analysis into a limits of acceptable change framework," Tourism Management, vol. 32, no. 1, pp. 128-140, 2017.

[32] A. Aubry, V. Carotenuto, A. De Maio, A. Farina, and L. Pallotta, "Optimization theory-based radar waveform design for spectrally dense environments," IEEE Aerospace and Electronic Systems Magazine, vol. 31, no. 12, pp. 14-25, 2017.

[33] S. Balaji and C. V. Brown, "Lateral coordination mechanisms and the moderating role of arrangement characteristics in information systems development outsourcing," Information Systems Research, vol. 25, no. 4, pp. 747-760, 2017. 